Ю. С. Лапина, И. А. Жерносенко. Диалектика «центра» и «периферии» в процессе становления культурной среды г. Барнаула в XVIII-XIX вв.

Научная статья

УДК 008.2

DOI: 10.18101/1994-0866-2020-4-39-48

\title{
ДИАЛЕКТИКА «ЦЕНТРА» И «ПЕРИФЕРИИ» В ПРОЦЕССЕ СТАНОВЛЕНИЯ КУЛЬТУРНОЙ СРЕДЫ Г. БАРНАУЛА В ХVIII-ХІХ вВ.
}

\author{
(C) Лапина Юлия Сергеевна \\ аспирант, \\ Алтайский государственный институт культуры \\ Россия, 656055, г. Барнаул, ул. им. А. Юрина, 277 \\ dirizher.yulya.92@mail.ru
}

\section{(C) Жерносенко Ирина Александровна}

доктор философских наук, доцент, профессор кафедры гуманитарных исследований, Алтайский государственный институт культуры

Россия, 656055, г. Барнаул, ул. им. А. Юрина, 277

irina.jernosenko@gmail.com

\begin{abstract}
Аннотация. Настоящая работа посвящена рассмотрению проблемы диалектического взаимодействия социокультурных категорий «центра» и «периферии», проявляющегося как гибкий нелинейный процесс, на примере становления г. Барнаула как центра европейской культуры в Сибири в XVIII-XIX вв. Базируясь на диалектическом методе, в своем исследовании авторы используют центрпериферийную схему с целью выявления направленности и динамики культурного развития, концентрируя внимание на амбивалентной природе эволюции городской культурной среды Барнаула. В качестве исходной точки формирования городской среды Барнаула авторы выделяют единственный производственнотехнический центр за Уралом - Барнаульский сереброплавильный завод, вокруг которого сформировалась жизнеобеспечивающая инфраструктура, впоследствии обусловившая превращение города-завода в культурный центр. В контексте представленной проблемы авторы рассматривают явление «феномена Петербургии» в Барнауле, проявлявшегося в целом ряде аналогий и сходств с Санкт-Петербургом в планировании, обустройстве и культурной жизни города. Диалектика функционирования бинарной оппозиции «центр - периферия» проявляется и в обратном влиянии Барнаула на Санкт-Петербург в частности и в его роли как периферийного промышленного центра, существенно повлиявшего на становление оборонного и экономического потенциала Российской империи в целом. В результате исследования авторы констатируют формирование в Алтайском горном округе особого типа региональной культуры, специфика которой обусловлена центрпериферийной моделью социокультурного взаимодействия.
\end{abstract}

Ключевые слова: культурная среда; культура Барнаула; региональная культура; центр; периферия; центр-периферийное взаимодействие; «феномен Петербургии».

\section{Для цитирования}

Лапина Ю. С., Жерносенко И. А. Диалектика «центра» и «периферии» в процессе становления культурной среды г. Барнаула в XVIII-XIX вв. // Вестник Бурятского государственного университета. Философия. 2020. Вып. 4. С. 39-48. 
В рамках рассмотрения проблематики одной из базовых философских категорий — категории «пространство» - значительным эвристическим потенциалом обладает ее культурологический аспект: соотношение между локусами центром и периферией, вернее, их диалектическое единство.

Выделение «центра» и «периферии» в пространственно-временном континууме той или иной историко-культурной эпохи позволяет увидеть наиболее обобщенные и универсальные отношения между различными точками и областями социокультурного пространства, что, в свою очередь, способствует наиболее полному отражению действительности в ее пространственном измерении с учетом количественно-качественного характера изменений, проявляющихся в возникновении конкретных социокультурных феноменов.

Бинарная оппозиция «центр - периферия» междисциплинарна по своей природе и широко распространена в современной гуманитарной науке. Исследователь Г. А. Коваленко отмечает, что под «центро-периферической структурой... следует понимать... обобщенное выражение неравномерного распределения материальных и нематериальных благ и возможностей между людьми», в то время как «центр и периферия на различном уровне пространства связаны между собой потоками информации, капитала, товаров, рабочей силы и т. д.» [1, с. 45]. Так, использование оппозиции «центра» и «периферии» более чем характерно для истории и географии, а также экономического и политического знания. Данный подход, продемонстрировавший свою эффективность в названных областях социально-гуманитарного знания, применим и в рамках культурологического исследования, что позволяет обозначить ориентацию и точки притяжения культурного потенциала населения исследуемой территории, векторы ее культурного развития, направления и интенсивность информационного обмена.

Схема взаимодействия «центра» и «периферии» диалогична, характеризуется универсальностью и гибкостью, сложностью и нелинейностью социокультурных процессов. Иногда периферийные территории, в силу сложившихся исторических условий, могут принимать на себя управленческие функции, становясь своеобразным «центром».

Диалоговая природа взаимодействия центра и периферии предполагает концентрацию культурного потенциала с последующим его распространением на периферию, стремящуюся к его поддержанию и развитию в качестве обратной связи. Подобный феномен формирования амбивалентной социокультурной среды возник в XVIII-XIX вв. на периферийной территории Российской империи на Алтае, в землях Колывано-Воскресенского горного округа, богатых полиметаллическими рудами где в начале XVIII в. уральский заводчик Акинфий Демидов начал строить город-завод Барнаул, превратившийся через сто лет в центр столичной культуры («Петербургии») в Сибири.

Для осмысления логики и динамики общероссийских процессов названного периода достаточно эвристичным, на наш взгляд, может оказаться индуктивный метод рассуждения: от конкретных регионов, где «многообразие связей типологически подобно общероссийскому, но в силу локализованности во времени и пространстве они носят более очевидный характер» [2]. Общероссийский экономический, политический, историко-культурный контекст, конечно, задавал опре- 
Ю. С. Лапина, И. А. Жерносенко. Диалектика «центра» и «периферии» в процессе становления культурной среды г. Барнаула в XVIII-XIX вв.

деленные тренды развития регионов, но именно конкретные региональные условия, наличие или отсутствие культурных пассионариев, эффективных управленцев и т. п. создавали неповторимый облик самих регионов, а также оказывали значимое влияние на столичный центр. Именно подобная уникальность условий и неравномерность развития регионов очень тонко были подмечены в середине XIX в. молодым путешественником и исследователем Сибири П. П. СеменовымТян-Шанским: «Общество [Барнаула - $a в m$.], всё однородное, состояло из очень хорошо образованных и культурных горных офицеров и их семейств, сильно перероднившихся между собою, а также семейств 2-3-х золотопромышленников, отчасти бывших в свое время также горными офицерами. Жили они весело и даже роскошно, но в их пирах не было той грубости, которой отличались оргии членов Главного управления Западной Сибири в Омске. Эстетические наклонности горных офицеров проявлялись не только в убранстве их комнат и изящной одежде их дам, но и в знакомстве как с научной, так и художественной литературой и, наконец, в процветании барнаульского любительского театра, который имел даже свое собственное здание. Одним словом, Барнаул был в то время, бесспорно, самым культурным уголком Сибири, и я прозвал его Сибирскими Афинами, оставляя прозвище Спарты за Омском» [3, с. 13].

В XVIII в. в Российской империи наблюдается становление тяжелой, в том числе горнорудной и металлургической, промышленности (наиболее сконцентрированной на Урале и на Алтае), что к XIX в. определило капиталистический вектор развития страны. Формирование свободной конкуренции и рынка наемного труда, а также новых социальных слоев обусловило кризис крепостничества. Если в XVIII в. на заводах работали крепостные рабочие, набиравшиеся из крепостных крестьян окрестных деревень, так как горнорудное и металлургическое производство, относившееся к военно-промышленному комплексу, всецело было подведомственно Царскому кабинету, и государство на эти предприятия осуществляло поставку рабочей силы, то ко 2-й половине XIX в. ситуация претерпела существенные изменения: бо́льшая часть производства тяжелой и тем более легкой промышленности, вырастающей из мануфактурных производств, стала принадлежать частным владельцам, использовавшим наемный труд.

Становление российского капитализма не могло не оказывать влияния на сферу культуры и образования. Развитие сложного производства потребовало расширения круга образованных лиц не только в сфере руководящего и инженерного состава, но и среди рабочих. К середине XIX в. формируется новый слой так называемой разночинной культуры, культуры представителей средних и низших сословий, в том числе крестьянства, получивших доступ к образованию. Существенную роль в этом процессе сыграло ускорение роста городского населения за счет притока крестьян на заработки в промышленной сфере. Именно урбанизацию правомерно считать основополагающим фактором формирования того самого «важнейшего универсального механизма всего культурного процесca, проявившегося в двуединстве развития городской культуры. Суть его сводится к постоянному взаимодействию между "центром" и "периферией"» $[4$, с. 20 24]. Спецификой устройства этого механизма объясняется неравномерность рас- 
пределения городской культуры разных регионов Российской империи, а также различные темпы городского развития.

Характерно, что модель типа «центр - периферия», применённая к городской культуре Барнаула, способна выявить неочевидные вариативные связи. Барнаул изначально закладывался Царским кабинетом с подачи Акинфия Демидова как город-завод - промышленный и экономический «центр» горнорудного производства в Сибири, значительно превышающего уральские запасы полезных ископаемых. Будучи географической «периферией» Российской империи, провинциальный Барнаул, благодаря тесным контактам со столичным СанктПетербургом, откуда приезжали специалисты горнорудного производства, осуществлялось административное и экономическое управление, сразу же стал играть роль центра промышленного производства в Сибири, что, в свою очередь повлияло на его становление в качестве экономического и культурного центра, концентрирующего в себе не только собственно культурную жизнь, но также и производственную основу, предоставляющую широким слоям населения (в том числе иногороднего) рабочие места.

Развитие Барнаула в рассматриваемый нами период связано с так называемым феноменом Петербургии, заключающимся в проявлении аналогий и сходств с Санкт-Петербургом в концептуальном планировании города и его обустройстве. В Барнауле это проявляется в планировке улиц - «линий»; облике первого барнаульского храма, посвященного святым Петру и Павлу, напоминавшего петербургский Петропавловский собор; ансамблях Петропавловской улицы и Демидовской площади, следовавших принципам русского классицизма, рожденного в Петербурге [5, с. 98-100]. Главный командир КолываноВоскресенских заводов Г. С. Качка отправил в Петербург для обучения архитектуре в Академии художеств двух смышленых юношей, ставших первыми зодчими Барнаула: «А. И. Молчанов работал на строительстве сооружений Дж. Кваренги, а Я. Н. Попов на протяжении семи лет учился у К. И. Росси, привезя на родину главный принцип россиевского творчества - формирование городского пространства через ансамблевые архитектурные комплексы...» [6, с. 105]. Подобный прецедент можно рассматривать как частный случай проявления центро-периферийных отношений — «большой и маленький Петербург», где Барнаул представляется в качестве малой «копии» столицы.

Еще один аспект проявления «феномена Петербургии» в Барнауле заключается в реализации петровской политики продвижения способных выходцев из народа в сферы науки и техники. Так, ключевую роль в истории развития культуры Барнаула сыграла деятельность Главного командира КолываноВоскресенских заводов, губернатора Томской губернии Петра Козьмича Фролова, который, подобно Петру I, внес ряд прогрессивных изменений в административное устройство города, формирование городской среды и, следовательно, быт местного населения. Важно заметить то, что в своей активной деятельности по преобразованию города Барнаула и системы управления им П. К. Фролов во многом руководствовался опытом, полученным им во время обучения в СанктПетербургском горном институте, который он окончил в 1793 г. Именно П. К. Фролов стал инициатором строительства архитектурного ансамбля на Де- 
Ю. С. Лапина, И. А. Жерносенко. Диалектика «центра» и «периферии» в процессе становления культурной среды г. Барнаула в XVIII-XIX вв.

мидовской площади, основания в 1823 г. и последующего наполнения фондов первого в Сибири краеведческого музея (совместно с естествоиспытателем и врачом Фридрихом Геблером) [7, с. 20-21]. Будучи высокообразованным и культурным человеком, П. К. Фролов хорошо разбирался в архитектурном искусстве и привлекал к строительству дипломированных архитекторов, так же, как и он, обучавшихся в Санкт-Петербурге и способных привнести в барнаульский облик столичные черты [8]. Так, например, А. И. Молчанов, сопровождавший караван с серебром в Санкт-Петербург, впоследствии поступил в Академию художеств, а вернувшись на Колывано-Воскресенские заводы в 1827 г., получил крупные заказы на проектирование таких зданий, как плавильная фабрика, богадельня, горное училище [9].

Барнаульский завод послужил точкой оформления городской среды, развитие которой далее регламентировалось и направлялось административными органами империи, так как он являлся единственным производственнотехническим центром за Уралом. Вокруг сереброплавильного завода, включающего в себя такие учреждения, как канцелярия, «инструментальный магазин» (склад готовой продукции), горно-химическая лаборатория, чертежная мастерская, выстраиваются специфические социально-экономические отношения, основанные на закрепощении рабочих. Также развитие завода обусловило формирование жизнеобеспечивающей инфраструктуры (горное училище, горный госпиталь, богадельня). Такая инфраструктура приводит к превращению города-завода в культурный центр, что проявляется в закономерном появлении таких учреждений, как библиотека, архив, типография, театр, картинная галерея, военный оркестр, а также метеорологическая станция, оранжерея и т. п. [6, с. 106].

Политика Царского кабинета в отношении Барнаула способствовала созданию и поддержке учреждений культуры столичного типа. Это было востребовано городским населением, среди которого было достаточно выпускников петербургских учебных заведений. Служащие горного ведомства и заводские рабочие получали образование не только в Барнаульском горном училище. Его выпускники, проявившие выдающиеся способности, продолжали свое обучение в столичном горном институте при финансовой поддержке барнаульской администрации. Этот фактор усиливался и тем, что в Барнауле как стратегически значимом для обороноспособности страны промышленном центре было запрещено поселение ссыльных и каторжников. В свою очередь, отсутствие в городе ссыльных революционеров, которые после отбывания наказания были оставлены для поселения в разных городах и селах Сибири и активно занимались просветительством, несколько замедляло развитие народного просвещения в Барнауле [6, c. 108].

В контексте проблематики настоящей работы необходимо отметить и обратное влияние Барнаула на Санкт-Петербург (хоть и, разумеется, менее значительное). Примером тому служит появление в Петербурге сооружений в стиле промышленного классицизма, впервые примененного на Урале и на Алтае, где было принято возведение промышленных зданий в классицистских традициях и приближение их визуального облика к зданиям общественным [10, с. 96]. Также существенным оказалось влияние социального аспекта бинарной оппозиции 
«центр - периферия»: определенная часть чиновников и представителей технической интеллигенции, а также исследователей природы Алтая и ее ресурсов, вернулась в Петербург на службу в административные органы, обогащенная уникальным практическим опытом.

Горнопромышленная ориентация Алтайского горного округа и его принадлежность Царскому кабинету поставили Алтай в достаточно выгодные условия социокультурного развития по сравнению с другими горнодобывающими районами. Значимость внешних контактов Барнаула со столицей подчеркивались современниками. Сошлемся на свидетельство Г. Н. Потанина: «До пяти раз в год из Барнаула отправлялся в Петербург караван с золотом под начальством одного из инженеров, который возвращался из столицы со всякого рода новостями. Ни один город в Сибири не имел с Петербургом таких частых и правильных обновляющих местную жизнь сношений, и эта особенность давала право барнаульским инженерам говорить, что Барнаул - уголок Петербурга» [11, с. 254].

В совокупности вышеназванные факторы дают основание говорить о формировании в Алтайском горном округе особого типа региональной культуры, реализующей амбивалентный процесс социокультурного развития «центр - периферия», основанный, с одной стороны, на внимании государственной администрации к научно-технологическим и социально-экономическим процессам становления города-завода Барнаула, а с другой - на продуманной социальнокультурной политике местной администрации, проявляющейся в поддержке горнозаводской интеллигенции, образовании талантливых выходцев из среды рабочих завода, создании культурной среды города и т. п., - все это способствовало тому, что «к концу XVIII в. алтайские заводы заняли ведущее место в России по организации управления производством, системе подготовки специалистов и составу кадров технической интеллигенции. Накопленным опытом Алтай делился с другими горнодобывающими районами страны...» [12, с. 21].

Интересно отметить специфику духовного пространства горного города Барнаула. Помимо того, что к середине XIX в. Барнаул занимал позиции одного из самых образованных городов Российской империи: 57\% его населения была грамотной, так как состояла из служащих городского ведомства, обладавших высшим и средним специальным образованием, и заводских рабочих с семьями, которые должны были иметь хотя бы начальное образование [5, с. 94], барнаульцы также вели довольно насыщенную культурную жизнь, о чем свидетельствует наличие Оперного дома, традиции домашнего музицирования, а также наличие нескольких оркестров.

Особую, регламентирующую функцию в управлении производством в Алтайском горном округе играла военная музыка, по природе своей призванная повышать дисциплинированность и сплоченность в строю. Так как Императорская канцелярия Колывано-Воскресенских горных заводов входила в военнопромышленный комплекс Российской империи, то и стиль руководства Алтайским горным округом, и звания офицеров округа подчинялись военному регламенту. А военная музыка стала неотъемлемой частью городского быта. Один из выдающихся капельмейстеров, руководитель городского военного оркестра капрал Степан Иванов, помимо непосредственного сопровождения всех мероприя- 
Ю. С. Лапина, И. А. Жерносенко. Диалектика «центра» и «периферии» в процессе становления культурной среды г. Барнаула в XVIII-XIX вв.

тий военно-горного строя, организовывал концерты военного оркестра, музыкальные вечера, а также открыл первую в Барнауле музыкальную школу [6, c. 116].

Пристрастия местной административной элиты к музыке, театру, литературе начали складываться еще в период правления Екатерины II. Приобретением музыкальных инструментов и аксессуаров к ним занимались главные командиры Колывано-Воскресенских заводов (А. И. Порошин, А. А. Ирман, Б. И. Меллер, Г. С. Качка) и местные музыканты $[13$, с. 28]. Военные оркестры и «светские ансамбли могли выступать как на официальных церемониях, так и на различных увеселительных гражданских мероприятиях — балах, концертах и т. д.» [14, c. 146].

Постепенно в городе укоренялась и невоенизированная светская музыкальная культура. Если поначалу ее «очагами были дома высокопоставленных чиновников-аристократов, приехавших из центральной части страны, где формировались традиции новой российской культуры, то последняя треть XVIII в. характеризуется распространением светской культуры в более широкие слои общества» [15, с. 596-597]. Открытие Оперного дома в 1776 г. внесло в культурную жизнь барнаульцев столичный лоск. Горные офицеры Алтайского округа, получившие образование в Петербурге, привезли в Барнаул традицию проведения культурного досуга в театре. Они же вместе с супругами сформировали основной состав исполнителей. Дело в том, что для представителей дворянских званий было характерно посещение музыкальных и танцевальных занятий, обучение иностранным языкам, входившие не только в систему их домашнего обучения, но и являвшиеся атрибутом принадлежности к определенному сословию [13]. «Помимо музыкальных спектаклей, на сцене театра нередко давались музыкальные вечера и концерты военного оркестра» [5, с. 177]. Исполнение любительских спектаклей барнаульского Оперного дома проходило на высоком профессиональном уровне, о чем не раз свидетельствовали путешественники, оказывавшиеся в Барнауле [7].

Значимым фактором демократизации культуры, выразившейся прежде всего в активизации народного просвещения в Барнауле, является появление ссыльных после реформы 1861 г. В связи с этим меняются жанровые приоритеты музыкальной культуры Барнаула: теперь особое место получает хоровая музыка, которая изначально носила прикладной характер: звучала в ходе церковной службы в храмах. Но именно благодаря церковной музыке происходило приобщение жителей Барнаула к вокально-хоровому исполнительству, что в дальнейшем приведет к созданию любительских хоров певчих и светских хоровых коллективов ${ }^{1}$. В 1890-е гг. зарождается новая форма выступлений — «духовные концерты».

В начале 1890-х гг. местная интеллигенция, любящая музицировать, объединилась в «Барнаульский музыкальный кружок». Главной задачей кружка являлось «давать возможность своим членам собираться для исполнения музыкальных произведений, а также способствовать развитию музыкальных

\footnotetext{
${ }^{1}$ Сибирский вестник. 1899. № 103.
} 
талантов среди своих членов» ${ }^{1}$. Для достижения этой цели устав предполагал «предоставление помещения, устройство библиотеки, устраивать домашние и публичные музыкальные вечера и концерты» ${ }^{2}$. Согласно принятому уставу, в начале марта 1895 г. музыканты кружка начали регулярно выступать в зале клуба Горного собрания.

Резюмируя вышесказанное, констатируем: Барнаул является репрезентативным примером действия бинарного механизма социокультурного развития «центр - периферия», что демонстрируется формированием специфической культурной среды города-завода как культурного центра Сибири, испытывающего мощное влияние столицы. С другой же стороны, будучи географической периферией по отношению к столице, Барнаул оказывал существенное влияние на становление оборонного и экономического потенциала Российской империи. Все это стало возможно, опять же, благодаря двунаправленным усилиям как со стороны Царского кабинета, так и со стороны местной администрации, сформированной из приезжей столичной интеллигенции и выращенных собственных талантливых выходцев из интеллигентской и разночинной среды, обученной в столице и местном горном училище (по сути — филиале Санкт-Петербургского горного института).

\section{Литература}

1. Коваленко Г. А. Центр и периферия в системе отношений органов управления культурой // История федерализма в России. К 100-летию образования Автономной Башкирской Республики: сборник материалов Всероссийской научно-практической конференции. Стерлитамак, 2018. С. 44-52.

2. Мурзина И. Я. Методологические аспекты изучения региональной культуры (к постановке проблемы) [Электронный ресурc]. URL: http://socioline.ru/files/murzina.pdf (дата обращения: 14.01.2015).

3. Барнаул. История культуры / сост. И. Н. Свободная. Барнаул, 2000. 184 с.

4. Социально-культурные функции города и пространственная среда / под ред. Л. Б. Когана. М., 1982. 177 с.

5. Культура Алтая: пособие для учителя / науч. ред. И. А. Жерносенко. Барнаул: АКИПКРО, 2016. $253 \mathrm{c}$.

6. Жерносенко И. А., Балакина Е. И. Культура Сибири и Алтая. Барнаул: Изд-во Жерносенко С. С., 2011. 208 с.

7. Жерносенко И. А., Шалабод М. Л. Любимый город. Барнаул — маленький Петербург. Барнаул: АКИПКРО, 2004. Ч. ІІ. 38 с.

8. Усанова А. Л. Художественное пространство Барнаула: диалектика столичной и провинциальной культуры // Вестник славянских культур. 2019. Т. 51. С. 277-288.

9. Первые архитекторы Колывано-Воскресенских заводов / А. А. Борисова, О. А. Осотова, А. В. Поднебеснов, Н. С. Трачук // Баландинские чтения. 2012. № 1. С. 12-16.

10. Нестерова С. В. Формирование культурного пространства города Барнаула в XVIII — начале XX в. : дис. ... канд. культурологии: 24.00.02. Кемерово, 2000. 276 с.

${ }^{1}$ Сибирский вестник. 1895. № 61.

2 Там же. 
Ю. С. Лапина, И. А. Жерносенко. Диалектика «центра» и «периферии» в процессе становления культурной среды г. Барнаула в XVIII-XIX вв.

11. Потанин Г. Н. Города Сибири // Сибирь, ея современное состояние и ея нужды. Санкт-Петербург, 1908.

12. Каратыгина Т. Ф. История технических библиотек в СССР. М., 1981. 166 с.

13. История культуры и музыкального образования на Алтае / сост. В. А. Виноградов; Алт. гос. ин-т. культуры, каф. нар. инструментов и оркестрового дирижирования. Барнаул: Изд-во АГИК, 2018. 119 с.

14. Нестерова С. В. Искусство сибирской провинции. Музыкальная жизнь Барнаула XIX - начала XX в. // Известия Алтайского государственного университета. Серия: Филология и искусствоведение. 2010. 2/2. С. 145-147.

15. Сибирская советская энциклопедия: в 4 т. / под общ. ред. М.К. Азадовского [и др.]. Новосибирск, 1932. Т. III. 804 с.

16. Виноградов В. А. Музыкально-театральная культура Барнаула в конце XVIII века // Хранители наследия / гл. ред. А. С. Кондыков [и др.]. Барнаул: Изд-во АГИИК, 2003. Вып.1. С. 127-130.

Статья поступила в редакцию 16.10.2020; одобрена после рецензирования 30.10.2020; принята к публикации 25.11.2020.

\title{
DIALECTICS OF THE CORE AND THE PERIPHERY \\ IN THE DEVELOPMENT OF THE CULTURAL ENVIRONMENT \\ OF BARNAUL IN THE $18^{\text {th }}-19^{\text {th }}$ CENTURIES
}

\author{
Yuliya S. Lapina \\ Research Assistant, \\ Altai State Institute of Culture \\ 277 im. A. Yurina St., Barnaul 656055, Russia \\ dirizher.yulya.92@mail.ru \\ Irina A. Zhernosenko \\ Dr. Sci. (Philos.), A/Prof., \\ Prof. of Humanities Department \\ Altai State Institute of Culture \\ 277 im. A. Yurina St., Barnaul 656055, Russia \\ irina.jernosenko@gmail.com
}

Abstract. The article deals with the problem of dialectical interaction between the sociocultural categories of the core and the periphery manifested as a flexible nonlinear process, as illustrated by the development of the city of Barnaul as a center of European culture in Siberia in the $18^{\text {th }}-19^{\text {th }}$ centuries. Based on the dialectical method, we use the core-periphery scheme in order to identify the course and dynamics of cultural development, focusing on the ambivalent nature of evolution of Barnaul's urban cultural environment. As the starting point for the development of Barnaul's urban environment we have identified one production and technical center beyond the Urals - Barnaul Silver Smelting Plant, around which a life-supporting infrastructure was formed, and subsequently company town transformed into a cultural center. In this context, we consider the phenomenon of "Petersburgia" in Barnaul, which is manifested in a number of analogies and similarities with St. Petersburg in the planning, infrastructure development and cultural life. The dialectics of the binary opposition "core-periphery" is also manifested in the reverse influence of Barnaul on St. Petersburg, in particular, in the role of Barnaul 
as a peripheral industrial center, which significantly influenced the development of the defense and economic potential of the Russian Empire. The study shown the development of a special type of regional culture in Altai Mountain District, which specificity was conditioned by the core-periphery model of socio-cultural interaction.

Keywords: cultural environment; culture of Barnaul; regional culture; the core; the periphery; core-periphery interaction; the phenomenon of "Petersburgia". 